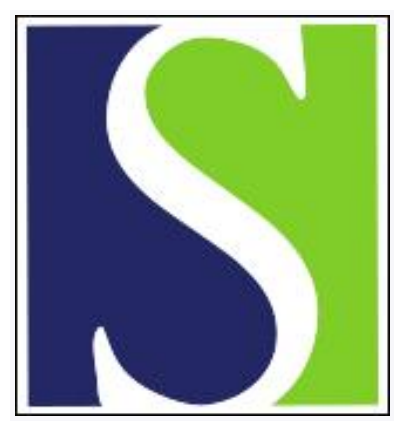

Scand J Work Environ Health 1980;6(2):112-122

https://doi.org/10.5271/sjweh.2624

Issue date: Jun 1980

Circadian variation of physiological functions related to physical work capacity.

by Ilmarinen J, Ilmarinen R, Korhonen O, Nurminen M

Key terms: circadian variation; periodic regression; physical work capacity; physiological function; work capacity

This article in PubMed: www.ncbi.nlm.nih.gov/pubmed/7433947

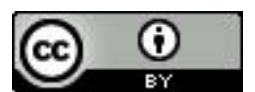




\title{
Circadian variation of physiological functions related to physical work capacity
}

\author{
by Juhani IImarinen, PhD, Raija IImarinen, PhD, Olli Korhonen, MD, \\ and Markku Nurminen, LSc ${ }^{1}$
}

\begin{abstract}
ILIMARINEN J, ILMARINEN R, KORHONEN O, NURIMINEN M. Circadian variation of physiological functions related to physical work capacity. Scand $j$ work environ health 6 (1980) 112-122. The circadian variation of selected physiological functions related to physical work capacity was studied in four trained young male subjects. The twofold objective was to describe, in parametric terms, the variation of these functions and estimate the times and values of their maximum and minimum responses. Statistically significant periodic regression effects were found for the following functions: oral temperature; systolic blood pressure; heart rate at rest, during work (245 and $270 \mathrm{~W})$ and after a 5-min recovery; ratings of perceived exertion; strength of hand grip; and neuromuscular coordination measured with a seesaw board balance test. The Fourier curve (sine curve) accounted for $63 \%$ of the variation in oral temperature and from 13 to $38 \%$ of the variation in the other significant harmonic intensities. In phase with the rhythm of oral temperature, but with larger amplitude, were systolic blood pressure, heart rate at rest and heart rate during work; roughly in phase were strength of hand grip and neuromuscular coordination. Ratings of perceived exertion and heart rate after a 5-min recovery showed a rhythm which was out of phase with the oral temperature. The number of disturbances in neuromuscular coordination was greatest at 2400 and smallest at 1200 , the difference being as large as $44 \%$. The results suggest that the measured capacities of muscle strength and neuromuscular coordination are the lowest, that physical work is perceived as the heaviest, and recovery after work is the slowest at night. These findings appear to support the notion that performance capacity is reduced during the night.
\end{abstract}

Key terms: periodic regression.

The circadian variation of physiological capacity and psychological performance has been the topic of earlier studies on shift work $(15,16)$. It has been suggested that an individual's capacity for doing mental or physical work is not the same throughout the waking period (9). Generally, performance during a night shift is worse than during a day shift (4).

Complaints made by shift workers have pointed to a sensation of reduced physical work capacity during the night. However

1 Institute of Occupational Health, Helsinki, Finland.

Reprint requests to: Dr Juhani Ilmarinen, Institute of Occupational Health, Laajaniityntie 1, SF-01620 Vantaa 62, Finland. study results contradict these complaints. A high physical work capacity has been measured during both the day $(17,20)$ and night $(8,18)$. No difference in maximal oxygen consumption $\left(\mathrm{VO}_{2} \max \right)$ between day and night was suggested by Wahlberg \& Astrand (19). The results of Ilmarinen et al (7) showed no circadian variation of various circulatory and respiratory functions at a submaximal work level, but at the maximum work level a decreased physical work capacity at night was demonstrated. They indicated that the 5$6 \%$ decrease in $\mathrm{VO}_{2} \max$ at night was probably of practical importance only when work is especially heavy.

Because physical work capacity is a combination of energy output, muscle strength, 
neuromuscular function, and psychological factors, we studied selected single variables including aerobic work capacity, strength of hand grip, technique of balance maintenance, and ratings of perceived exertion. The twofold objective of this study was to locate the statistical sources of variation and describe their characteristics as manifested in the aforementioned variables and also to estimate the times and values of the maximum and minimum responses of the variables.

\section{Subjects and methods}

\section{Subjects}

Four young (23-25 a of age) well-trained male volunteers were selected from a large class at a sports institute (table 1).

A medical checkup of each subject, including an exercise electrocardiogram, was performed by a physician.

\section{Time schedule}

The measurements were recorded in two stages. During the first stage two sets of the same measurements were taken. Each set was performed in a random sequence of the following times: $0700,1100,1500,1900$, 2300 and 0300 . This first stage was conducted during one week near the end of October 1973.

The second stage was divided into two parts, involving only two of the subjects each time. The two parts took place in January and February 1974, respectively. During this stage only one set of measurements was made. Although the time when the set was begun for each subject was different, once started the measure- ments were made at consecutive $4-\mathrm{h}$ intervals during a 24-h period. The times followed in the first stage were also used in the second, but not in random order. For the final statistical analysis the data from both stages were combined. Thus for each measurement some of the observations were made at the same point in time in the same $24-\mathrm{h}$ period, while others were made at the same time but in different 24-h periods.

\section{Variables and measurements}

Table 2 presents the 15 basic and 2 summated variables considered in this investigation.

The first measurement was of the strength of the hand grip. A special dynamometer was constructed especially for this purpose. The device comprised a fluid-filled elastic tube with a pressurestrain gauge transducer (Kyowa PG-10 KA) attached. When pressure was exerted, it was converted into an electrical signal, amplified, and displayed (Kyowa TMP$24 \mathrm{~A})$. At the same time the pressure curve was sketched on a graphic recorder (Goerz RE 511). The strength values were given in kilopascals. The meter's range was from 0 to $123 \mathrm{kPa}$. The stability and linearity of the measuring system was calibrated regularly with mechanical pressure equipment.

The position of the subject during the hand grip measurements was standardized. He lay on his back on the floor with his arms straight out at a $90^{\circ}$ angle to his body. A maximal measurement was taken from each hand, and then the measurement was repeated in the same order as the first one. The higher values of the two for each hand were used in the analysis.

Table 1. Characteristics of the subjects.

\begin{tabular}{cccccc}
\hline Subject & $\begin{array}{c}\text { Age } \\
(\mathrm{a})\end{array}$ & $\begin{array}{c}\text { Height } \\
(\mathrm{cm})\end{array}$ & $\begin{array}{c}\text { Weight } \\
(\mathrm{kg})\end{array}$ & $\begin{array}{c}\text { Maximal } \\
\text { heart rate } \\
\text { (beats/min) }\end{array}$ & $\begin{array}{c}\text { Maximal } \\
\text { oxygen } \\
\text { consumption } \\
(\mathrm{ml} / \mathrm{min} \times \mathrm{kg})\end{array}$ \\
\hline A & 24 & 179 & 75 & 175 & 70 \\
B & 23 & 186 & 95 & 190 & 54 \\
C & 25 & 174 & 60 & 190 & 76 \\
D & 23 & 188 & 83 & 175 & 66 \\
\hline
\end{tabular}

a Predicted value, mean of all measurements. 
The second measurement was of neuromuscular coordination. A balance test comprising a seesaw type of apparatus was developed for this purpose. The subject stood at a fixed place on the board and tried to reach and maintain his balance. The sensitivity of the apparatus was such that active neuromuscular coordination was required before a balanced state could be achieved. The allowed range of movement for each end of the board was set at $25 \mathrm{~mm}$. Each time this limit was exceeded and either end made contact with the floor plate, the sensitive microswitch in the tip of the board registered a disturbance in balance. An electrical counter recorded the number of contacts, and the total number of contacts in 1 min was used as the variable for analysis.

After these two tests the subject Nas allowed to rest by lying on a bed for 20 min. At the end of this rest period the subject's oral temperature $\left(\mathrm{T}_{0}\right)$ was taken with an ordinary mercury thermometer for 3 min. Next, while the subject was still lying down, his blood pressure was measured. The lowest heart rate recorded during the rest period was taken as the heart rate at rest.

The final measurement involved a submaximal bicycle ergometer test. Each subject was allowed a 2-min warm-up at $100 \mathrm{~W}$ on a bicycle ergometer (Monarck) and then $2 \mathrm{~min}$ of rest. Thereafter the subject worked for $3 \mathrm{~min}$ at a speed of 50 $\mathrm{r} / \mathrm{min}$ at each of the following work loads: $150,200,220,245$ and $270 \mathrm{~W}$, labeled I-V, respectively. No rest between loads was allowed. The loads were increased stepwise with a mechanical brake.

For each subject an electrocardiogram (ECG) was recorded (Mingograph), as well as the heart rate during work. The heart rate measurements were made during the time needed for 15 consecutive ECG R-R intervals to be recorded (10-15 s). The allotted times of measurement were in the final seconds of each minute the subject pedaled. A 5-min recovery period, during which the heart rate (heart rate recovery) was also measured, followed the work period.

When this test was repeated in the second stage of the investigation in the spring, it involved an additional measurement of oxygen consumption $\left(\mathrm{VO}_{2}\right)$ at three submaximal work loads. The Douglas-bag method was employed for this purpose.

The $\dot{\mathrm{VO}}_{2} \mathrm{max}$ was predicted from the regression equation between the heart rate and work load. The regression line was extrapolated to the maximal heart rate, which was actually measured while the subjects pedaled the bicycle ergometer. The predicted $\mathrm{V}_{2} \max$ was the oxygen consumption corresponding to the maximal work load value.

During the bicycle ergometer test the subjects' ratings of their perceived exertion were registered. A scale from 6 to 20 with verbal expressions such as "very light" and "very hard," as explained by Borg (2), was used. The ratings were given at the end of each work load. Subjects were instructed to rate the degree of exertion by saying aloud one number from the scale values.

During the test periods coffee, medicines, and all alcoholic drinks were forbidden. Food intake was forbidden $2 \mathrm{~h}$ before the beginning of the test. The subjects carried out their normal daily routines. Heavy sports activities were avoided. If the subject was sleeping, he was awakened $1 \mathrm{~h}$ before the test time.

\section{Statistical methods}

A given physiological variable that changes with time is called a time function, which implies that a given value depends on the time when it is sampled. Time functions are usually plotted along rectangular coordinates, with the physiological function $y$ shown on the ordinate and the time $t$ on the abscissa. This dependence may be expressed by the mathematical relationship $y=f(t)$, which means that $y$ is a function of $t$.

Analyses of physiological rhythms are closely allied with questions of periodicity. A periodic function can be defined as $f(t)=f(t+\tau)$, where $\tau$ is the period of the rhythm under study. For all the subsequent analyses of cyclic physiological data it was assumed that the period was circadian, or $\tau=24 \mathrm{~h}$.

The data from this investigation consisted of $k=6$ equally spaced discrete sample points per day from four individuals for $3 \mathrm{~d}$. The individual measurements were subjected to a transformation 
in two trials to correct for the difference in the mean levels between the different circadians. The transformulas employed were:

and

$$
\mathrm{y}_{\mathrm{rt}}^{\prime}=\mathrm{y}_{\mathrm{rt}}+\ddot{\mathrm{y}}-\overline{\mathrm{y}}_{\mathrm{r}}
$$

$$
\mathrm{y}^{\prime \prime}{ }_{\mathrm{rt}}=\mathrm{y}_{\mathrm{rt}} \overline{\mathrm{y}}_{\mathrm{y}} \overline{\mathrm{y}}_{\mathrm{r}}
$$

where $y_{r t}^{\prime} s(r=1,2,3, \ldots, f ; f$ is the number of series) are the original measurements made at the same numbered point $t$ $(\mathrm{t}=0,1 \ldots, \mathrm{k}-\mathrm{l})$ in time, $\mathrm{y}_{\mathrm{rt}}^{\prime}$ and $\mathrm{y}^{\prime \prime}{ }_{\mathrm{rt}}$ are the corresponding transformed values,

$$
\overline{\mathrm{y}}_{\mathrm{r}}=\underset{\mathrm{t}=0}{\left(\sum \mathrm{y}_{\mathrm{rt}}\right) / 6}
$$

is the mean value for the $r^{\prime \text { th }}$ series, and

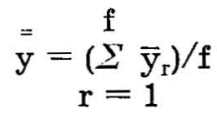

is the overall mean.

Harmonic analysis of the transformed time series consists of fitting, by leastsquares, the regression function of the form

$$
f(t)=m+r \cos (2 \pi t / k-\varphi),
$$

or, by rewriting the equation linearly in the adjustable parameters

$f(t)=m+a \cos (2 \pi t / k)+b \sin (2 \pi t / k)$, it is possible to produce estimates of the regression coefficients, $a, b$, and $m$. The point $(a, b)$ may equivalently be expressed in polar coordinates by a vector $\mathrm{r}=\left(\mathrm{a}^{2}+\right.$ $\left.b^{2}\right)^{1 / 2}$, where the phase angle corresponds to the direction of the vector $\varphi=\tan ^{-1}(\mathrm{~b} / \mathrm{a})$, and $\pi / \mathrm{k}$ in the circadian frequency ( 1 cycle/ $24 \mathrm{~h}$ ). Thus, the vector describes the amplitude $2 r$ and phase change in the harmonic function $f(t)$ about the mean $m$ (rhythm-adjusted level).

A periodic regression of a harmonic analysis program (BMD 04R, Health Sciences Computing Facility, UCLA) was applied in the computational procedure. Output from this program includes a table of observed (mean) values, values predicted by the model, their differences, and printed plots of the observed and predicted values for each harmonic successively.

We subjected the statistical model to an analysis of variance to ascertain the statistical significance of the contribution to the total variability made by the rhythm interpreted from the time plot. For an account of the proper tests of significance, the reader is referred to Bliss (1).
The estimation of the parameters of a given rhythm included computation of the circadian amplitude (the difference between the highest value and mean value in a sinusoidal oscillation, determined by harmonic analysis), the acrophase (phase angle of crest of function approximating the data), and the time of maximum and minimum response, based upon the average overall series.

From the inspection of the original (untransformed) series of measurements, it was difficult to discern a periodic course for the different physiological variables, except for oral temperature. The centering of the observations by the difference between the overall and mean values of the series eliminated this uninteresting (sum of squares) variation between the series. In effect, a Fourier curve was then fitted to each series, and the analysis of variance determined in what remaining respects these separate curves differed from series to series.

\section{Results}

\section{Periodic regression analysis}

In all, 14 of the measured or formed variables showed a statistically significant period regression effect (the sum of the effects of the harmonic coefficients) (table 2). The Fourier curve (sine curve) accounted for $63 \%$ of the variation in $T_{0}$, for 13 to $38 \%$ of the variation in the other significant intensities, and for 3 to $8 \%$ of that in the nonsignificant regressions.

\section{Oral temperature}

The mean square for scatter about the fitted average curve for $T_{0}$ was significantly larger than that for its residual variation, and we assumed that the deviations about the separate curves have a common element, as a result of which the probability of the regression effect is only "almost significant."

\section{Blood pressure}

A significant periodic regression $(p=$ 0.010 ) was observed for the systolic blood pressure. This result was confirmed with a modified Spearman rank test for the 
original variables, which gave an agreeable p-value of 0.014 .

The diastolic blood pressure showed no overall harmonic oscillation, a credible result in view of the many tied values within the series. Surprisingly, the analysis revealed the existence of a harmonic pattern which varied almost significantly between the 12 series. To separate the differences in amplitude and in phase, we subdivided the variation of the Fourier curve from series to series; it is represented in the last two columns of table 2. These values indicated that the amplitude or diurnal range was the significant variance component and not the phase or time of the maximum.

\section{Heart rate}

Heart rate at rest and during work load IV $(1,500 \mathrm{kpm} / \mathrm{min}$ or $245 \mathrm{~W})$ showed a highly significant periodic trend, which was less tractable during work load V $(1,600 \mathrm{kpm} / \mathrm{min}$ or $270 \mathrm{~W})(\mathrm{p}=0.025)$, probably due to the fact that there were only seven series available for the analysis.

Recovery heart rate varied diurnally on the average in a cyclic fashion, the variation being highly significant $5 \mathrm{~min}$ after work load IV and significant after work load V.

\section{Ratings of perceived exertion}

For the ratings of perceived exertion the analysis gave discrepant results, depending on the transformation. For the $\mathrm{y}^{\prime}$ variable the periodic regression was significant and the scatter about the average curve nearly significant $(\mathrm{p}=0.056)$, but for the $\mathrm{y}^{\prime \prime}$ variable the F-test statistic of the scatter component exceeded the critical level (corresponding to $\mathrm{p}=0.048$ ) when the periodic

Table 2. Analysis of variance of the studied physiological variables a: Summary of $p$-values for the sources of variation.

\begin{tabular}{|c|c|c|c|c|c|c|}
\hline $\begin{array}{l}\text { Physiological } \\
\text { variable }\end{array}$ & $\begin{array}{l}\text { Between } \\
\text { series }\end{array}$ & $\begin{array}{l}\text { Regres- } \\
\text { sion } \\
\text { effect } b\end{array}$ & $\begin{array}{l}\text { Scatter } \\
\text { about } \\
\text { curve }\end{array}$ & $\begin{array}{l}\text { Series } \\
\times \text { regres- } \\
\text { sion }\end{array}$ & $\begin{array}{l}\text { Series } \\
\text { Xampli- } \\
\text { tude }\end{array}$ & $\begin{array}{l}\text { Series } \\
\times \text { phase }\end{array}$ \\
\hline \multirow{9}{*}{$\begin{array}{l}\text { Oral temperature } \\
\text { Systolic blood pressure } \\
\text { Diastolic blood pressure } \\
\text { Heart rate at rest } \\
\text { Heart rate at } 1,500 \mathrm{kpm} / \mathrm{min} \\
(245 \mathrm{~W}) \\
\text { Heart rate at } 1,650 \mathrm{kmp} / \mathrm{min} \\
(270 \mathrm{~W}) \mathrm{c} \\
\text { Rating of perceived exertion } \\
\text { at } 1,500 \mathrm{kpm} / \text { min }(245 \mathrm{~W}) \\
\text { Heart rate recovery after } \\
1,500 \mathrm{kpm} / \mathrm{min}(245 \mathrm{~W}) \\
\text { Heart rate recovery after } \\
1,650 \mathrm{kpm} / \mathrm{min}(270 \mathrm{~W}) \mathrm{c}\end{array}$} & NS & $0.042 *$ & $0.0011 * *$ & NS & $0.028 *$ & NS \\
\hline & NS & $0.0099 * *$ & NS & NS & NS & NS \\
\hline & NS & NS & NS & $0.045 *$ & $0.012 *$ & NS \\
\hline & NS $\ll$ & $\ll 0.001 * * *$ & NS & NS & NS & NS \\
\hline & NS & $\ll 0.001 * * *$ & NS & NS & NS & NS \\
\hline & NS & $0.025 *$ & NS & NS & NS & NS \\
\hline & NS & $0.014 *$ & NS (0.056) & $0.042 *$ & NS & NS $(0.056)$ \\
\hline & NS & $\ll 0.001 * * *$ & NS & NS & NS & NS \\
\hline & NS & $0.003 * *$ & NS & NS & NS & NS \\
\hline $\begin{array}{l}\text { Predicted maximal oxygen } \\
\text { consumption (l/min) } \\
\text { Predicted maximal oxygen }\end{array}$ & NS & NS $(0.063)$ & NS & NS & NS & NS \\
\hline \multirow{3}{*}{$\begin{array}{l}\text { consumption }(\mathrm{ml} / \mathrm{min} \times \mathrm{kg}) \\
\text { Right-hand grip strength } \\
\text { Left-hand grip strength } \\
\text { Right- and left-hand grip }\end{array}$} & NS & NS & NS & NS & NS & NS \\
\hline & NS & $\ll 0.001 * * *$ & NS & NS & NS & NS \\
\hline & NS < & $<0.001 * * *$ & NS & NS & NS & NS \\
\hline strength & NS $<$ & $\ll 0.001 * * *$ & NS & NS & $0.045 *$ & NS \\
\hline Balance, right & NS & $0.014 *$ & NS & $0.0007 * * *$ & $0.003 * *$ & $0.003 * *$ \\
\hline Balance, left & NS & $0.003 * *$ & NS & NS & NS & NS \\
\hline Balance, right and left & NS & $0.006 * *$ & NS & $0.036 *$ & NS & $0.034 *$ \\
\hline
\end{tabular}

a Transformed variables y' (see methods).

b When both the scatter and the interaction of the first harmonic with series were nonsignificant, the significance of the regression effect was determined by reference to the residual variation, ie, total variance minus harmonic variance component.

c Data consisted of seven series only.

* $\mathrm{p}<0.05$, ** $\mathrm{p}<0.01$, *** $\mathrm{p}<0.001$. 
regression effect did not reach statistical significance (the appropriate approximate variance ratio of the F-test then being based on a linear combination of mean squares as the error variance). In both cases, however, the series differed from each other in the form of harmonics (mainly phase differences).

\section{Maximal oxygen consumption}

The probability level for predicted VO, max, when expressed in units of liter per minute, was on the verge of statistical significance for the $\mathrm{y}^{\prime}$ variable, which was corrected by an absolute difference in the mean level, but was just below the critical level $(0.049)$ for the $y^{\prime \prime}$ variate, for which the correction was done in relative terms.

\section{Strength of hand grip}

Highly significant harmonics were analyzed in the variables for the strength of hand grip, the left hand giving a slightly worse response. The combined variable (right- plus left-hand measurement) indicated that the series differed in amplitude almost significantly.

\section{Neuromuscular coordination}

The balance test values fitted well to a Fourier curve, the right side showing a slightly poorer overall fit resulting from the equally significant amplitude and phase interaction with the series.

\section{Estimation of harmonic intensities}

Table 3 presents the parametric results for the statistically significant harmonics. Parameter estimates are given both in rectangular $(\mathrm{a}, \mathrm{b})$ and polar coordinates $(\mathrm{r}, \varphi)$. The corresponding harmonic functions (Fourier curves) are presented in fig $1-3$. The rhythm of $T_{0}$ is shown for comparison with each variable. The most interesting derived data, however, are the estimated time and value of the maximum

Table 3. Periodic regression and harmonic analysis a of the studied physiological variables.b

\begin{tabular}{|c|c|c|c|c|c|c|c|c|c|}
\hline \multirow{3}{*}{ Physiological variable } & \multicolumn{3}{|c|}{ Parameter estimates } & \multicolumn{2}{|c|}{$\begin{array}{l}\text { Amplitude } \\
\text { phase angle }\end{array}$} & \multicolumn{2}{|c|}{$\begin{array}{l}\text { Maximum } \\
\text { response }\end{array}$} & \multicolumn{2}{|c|}{$\begin{array}{l}\text { Minimum } \\
\text { response }\end{array}$} \\
\hline & \multirow{2}{*}{$\underset{\text { (mean) }}{\text { Constant }}$} & \multicolumn{2}{|c|}{ Coefficients } & \multirow{2}{*}{$\underset{2 r}{\text { Range }}$} & \multirow{2}{*}{$\underset{\varphi}{\text { Radius }}$} & \multirow{2}{*}{$\begin{array}{l}\text { Esti- } \\
\text { mated } \\
\text { time } \\
\text { (hours } \\
\text { and } \\
\text { hun- } \\
\text { dreds) }\end{array}$} & \multirow{2}{*}{$\begin{array}{l}\text { Esti- } \\
\text { mated } \\
\text { value }\end{array}$} & \multirow{2}{*}{$\begin{array}{l}\text { Esti- } \\
\text { mated } \\
\text { time } \\
\text { (hours } \\
\text { and } \\
\text { hun- } \\
\text { dreds) }\end{array}$} & \multirow{2}{*}{$\begin{array}{l}\text { Esti- } \\
\text { mated } \\
\text { value }\end{array}$} \\
\hline & & a & $b$ & & & & & & \\
\hline $\begin{array}{l}\text { Oral temperature } \\
\text { Systolic blood pressure }\end{array}$ & $\begin{array}{r}36.4 \\
127.6\end{array}$ & $\begin{array}{l}-0.300 \\
-2.708\end{array}$ & $\begin{array}{l}0.236 \\
1.323\end{array}$ & $\begin{array}{l}0.76 \\
6.02\end{array}$ & $\begin{array}{l}2.48 \\
2.69\end{array}$ & $\begin{array}{l}16.46 \\
17.26\end{array}$ & $\begin{array}{r}36.8 \\
130.6\end{array}$ & $\begin{array}{l}04.46 \\
05.26\end{array}$ & $\begin{array}{r}36.0 \\
124.5\end{array}$ \\
\hline Diastolic blood pressure & $\begin{array}{l}78.9 \\
49.3\end{array}$ & -3.236 & 2.141 & 7.76 & 2.56 & 16.77 & 53.1 & 04.77 & 45.4 \\
\hline $\begin{array}{l}\text { Heart rate at } 1,500 \mathrm{kpm} / \mathrm{min} \\
(245 \mathrm{~W} \text { ) } \\
\text { Heart rate at } 1,650 \mathrm{kpm} / \mathrm{min}\end{array}$ & 146.3 & -1.444 & 1.828 & 4.66 & 2.24 & 15.55 & 148.6 & 03.55 & 144.0 \\
\hline $\begin{array}{l}(270 \mathrm{~W}) \\
\text { Rating of perceived exertion }\end{array}$ & 157.0 & -0.524 & 1.980 & 4.10 & 1.83 & 13.99 & 159.0 & 01.99 & 154.9 \\
\hline $\begin{array}{l}\text { at } 1,500 \mathrm{kpm} / \mathrm{min}(245 \mathrm{~W}) \\
\text { Heart rate recovery after } 1,500\end{array}$ & 15.7 & 0.361 & -0.241 & 0.87 & 5.70 & 04.76 & 16.2 & 16.76 & 15.3 \\
\hline $\begin{array}{l}\mathrm{kpm} / \mathrm{min}(245 \mathrm{~W}) \\
\text { Heart rate recovery after } 1,650\end{array}$ & 73.4 & 3.167 & -0.144 & 6.34 & 6.24 & 06.83 & 76.6 & 18.83 & 70.2 \\
\hline $\begin{array}{l}\mathrm{kpm} / \mathrm{min}(270 \mathrm{~W}) \\
\text { Predicted maximal oxygen }\end{array}$ & 80.4 & 2.024 & 1.608 & 5.17 & 0.67 & 09.56 & 83.0 & 21.56 & 77.8 \\
\hline $\begin{array}{l}\text { Consumption }(1 / \mathrm{min}) \\
\text { Predicted maximal oxygen }\end{array}$ & 5.08 & 0.732 & -0.960 & 2.41 & 5.36 & 03.49 & 5.20 & 15.49 & 4.96 \\
\hline consumption $(\mathrm{ml} / \mathrm{min} \times \mathrm{kg})$ & 64.0 & & & & & & & & \\
\hline $\begin{array}{l}\text { Right-hand grip strength } \\
\text { Left-hand grip strength } \\
\text { Right- and left-hand grip }\end{array}$ & $\begin{array}{l}71.5 \\
70.4\end{array}$ & $\begin{array}{l}-2.652 \\
-3.194\end{array}$ & $\begin{array}{l}0.394 \\
0.433\end{array}$ & $\begin{array}{l}5.36 \\
6.44\end{array}$ & $\begin{array}{l}2.99 \\
3.01\end{array}$ & $\begin{array}{l}18.44 \\
18.49\end{array}$ & $\begin{array}{l}74.2 \\
73.7\end{array}$ & $\begin{array}{l}06.44 \\
06.49\end{array}$ & $\begin{array}{l}68.8 \\
67.2\end{array}$ \\
\hline $\begin{array}{l}\text { strength } \\
\text { Balance, right } \\
\text { Balance, left } \\
\text { Balance, right and left }\end{array}$ & $\begin{array}{r}142.4 \\
15.3 \\
15.2 \\
30.4\end{array}$ & $\begin{array}{l}-6.030 \\
-0.542 \\
-0.986 \\
-1.528\end{array}$ & $\begin{array}{r}0.420 \\
-4.162 \\
-2.285 \\
-6.447\end{array}$ & $\begin{array}{r}12.09 \\
8.39 \\
4.98 \\
13.25\end{array}$ & $\begin{array}{l}3.07 \\
4.58 \\
4.31 \\
4.47\end{array}$ & $\begin{array}{l}18.73 \\
24.51 \\
23.44 \\
24.11\end{array}$ & $\begin{array}{r}148.4 \\
19.5 \\
17.7 \\
37.1\end{array}$ & $\begin{array}{l}06.73 \\
12.51 \\
11.44 \\
12.11\end{array}$ & $\begin{array}{r}136.4 \\
11.1 \\
12.7 \\
23.8\end{array}$ \\
\hline
\end{tabular}

a The harmonic analysis consisted of fitting, by least-squares, the regression function of the form $f(t)=m+r$ cos $\left[2 \pi\left(t-t_{0}\right) / x-\varphi\right]$ or $f(t)=m+a \cos \left[2 \pi\left(t-t_{0}\right) / \tau\right]+b \sin \left[2 \pi\left(t-t_{0}\right) / \tau\right]$, where $t=$ time (h), $t_{0}=$ starting point for measuring time (at 0700$), \tau=$ circadian $(24 \mathrm{~h})$, and $\mathrm{m}, \mathrm{a}$ and $\mathrm{b}$ (or equivalently $\mathrm{r}, \varphi$ ) are regression coefficients.

b Transformed variables $y^{\prime}$.

c Transformed variable $y^{\prime \prime}$. 
and minimum response. Since the sine curve is symmetrical, the time for the minimum is one-half a cycle before or after the time of the maximum.

\section{Oral temperature and blood pressure}

The maximum and minimum responses for $\mathrm{T}_{0}$ (fig 1a) and systolic blood pressure were estimated to occur at nearly the same time of day (fig $1 \mathrm{~b}$ ). The estimated maximums occurred at 1600-1700 and the minimums at $0400-0500$. The difference between the maximum and minimum calculated as the percentage of the constant mean was $2.2 \%$ for $\mathrm{T}_{0}$ and $4.8 \%$ for systolic blood pressure.

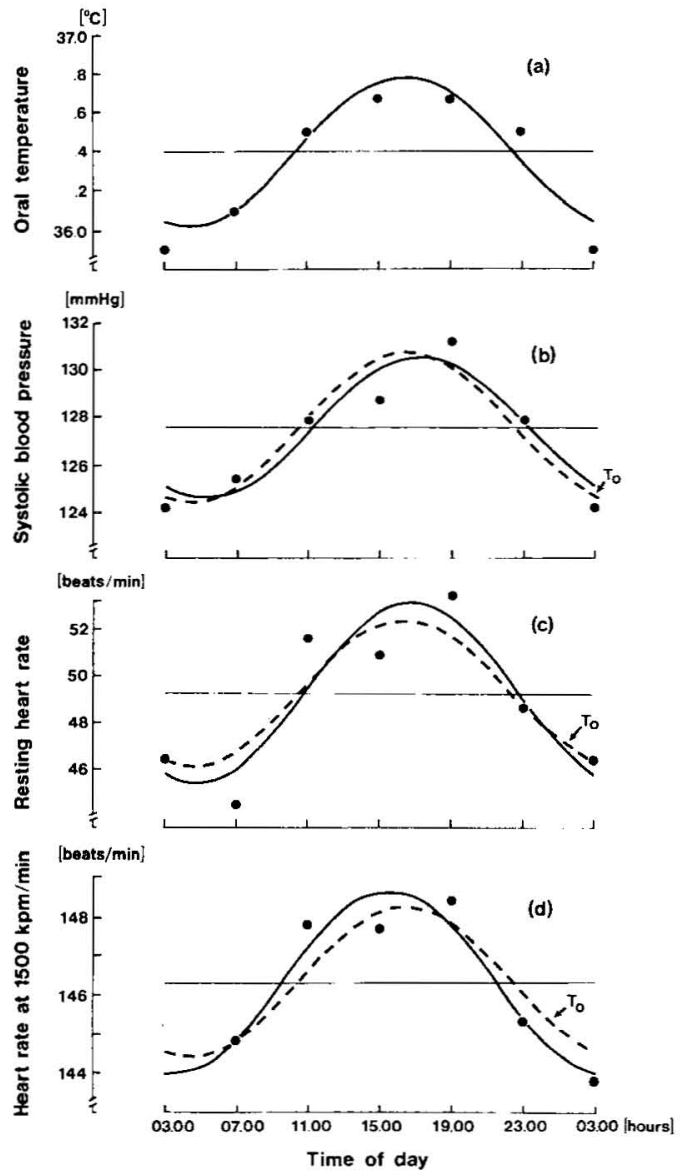

Fig 1. Fourier curves of the average hourly responses of oral temperature (a), systolic blood pressure (b, solid line), heart rate at rest (c, solid line) and heart rate at $1,500 \mathrm{kpm} / \mathrm{min}$ (245 W) (d, solid line). In b, c and $d$ the broken line represents the Fourier curve of oral temperature.
Heart rate at rest and during work

Generally, the maximum responses of the heart rate variables were predicted during the day and minimum responses during the night or early morning. The maximum value for heart rate at rest came late in the afternoon (1700) and the minimum at night (0500) (fig 1c). The difference between the minimum and maximum was $15.6 \%$, and it was larger than the corresponding range for heart rate during work or recovery. The smallest difference of 2.6 to $3.1 \%$ was found for heart rate during work, for which the maximum response was estimated to occur at $1400-1600$, and the minimum at $0200-0400$ (fig $1 \mathrm{~d}$ ).

\section{Oxygen consumption}

The directly measured $\dot{\mathrm{VO}}_{2}$ at three submaximal work loads showed no significant differences between the six sample points in $24 \mathrm{~h}$ (an analysis of variance test). The predicted $\mathrm{VO}_{2} \max (\mathrm{l} / \mathrm{min})$ showed a range of $4.7 \%$ between the minimum at $1500-$ 1600 and the maximum at $0300-0400$ and thereby reflected the maximum and minimum responses of heart rate at work.

\section{Strength of hand grip}

The maximum response for the variables of hand grip strength was estimated to occur near 1900 and the minimum at 0700 . The difference between the maximum and minimum varied from 7.6 (right) to 9.2 (left) $\%$ and was $8.4 \%$ for both hands (fig 2a).

\section{Neuromuscular coordination}

The maximum response for the variables of neuromuscular coordination (balance test) was calculated to occur at 2400 and the minimum at 1200 . The difference between the maximum and minimum in the number of disturbances on the right-hand side was as high as $55 \%$. For the lefthand side the respective difference was $33 \%$, while for both sides combined it was $44 \%$ (fig $2 b$ ). 
Heart rate recovery and ratings of perceived exertion

The heart rate response after a 5-min recovery period from working with work loads IV and $\mathrm{V}$ attained its maximum in the morning (0700-1000) and its minimum in the evening (1900-2200) (fig 3a). The difference between the minimum and maximum recovery heart rate for work load IV was $8.7 \%$ and that for work load V $6.5 \%$.

The ratings of perceived exertion during work load IV were at a maximum at $\mathbf{0 5 0 0}$ and at a minimum at 1700 . These times were the opposite of the heart rate response during work, and they suggest that perceived exertion is the highest at night even though the work heart rate is at its lowest point at that time (fig $3 b$ ).

\section{Discussion}

In meeting the assumptions of the analysis of variance, the adoption of a suitable unit for the response variate is often critical. Since the logarithms of many physiological measurements are normally distributed, the logarithmic transformation should be of equal value in periodic regressions. Since $\log \mathrm{y}^{\prime \prime}{ }_{\mathrm{rt}}=\log \mathrm{y}_{\mathrm{rt}}+\log \mathrm{y}-\log \overline{\mathrm{y}}_{\mathrm{r}}$, it can be seen that the transformation $y^{\prime \prime}$ is nothing but $\mathrm{y}^{\prime}$ expressed on a logarithmic scale. In addition, because both $\mathrm{y}^{\prime}$ and $y^{\prime \prime}$ yielded nearly equal results, we tacitly assumed that the variables $y^{\prime}$ can be analyzed as if they were approximately normally distributed.

The applied method of harmonic analysis assumes that any correlation between successive observations within a series is removed in the interaction of series by a and $b$. In our case of six variables it was found (table 2) that the data were not stationary in time, ie, over successive cycles the amplitude, phase, or both varied significantly. To study cyclic biological phenomena closer in an experiment designed to produce changes in amplitude or phase, a method (summation dial) based on vectors expressed in polar coordinates could have been applied (5). Unfortunately, the needed computing routines were not available.
In their review Rutenfranz \& Colquhoun (15) suggested that there are two main types of performance rhythm. One is roughly in phase with the rhythm of body temperature, and the other is considerably out of phase with this function.

The $\mathrm{T}_{0}$ in our study was taken as the reference variable of circadian variation.

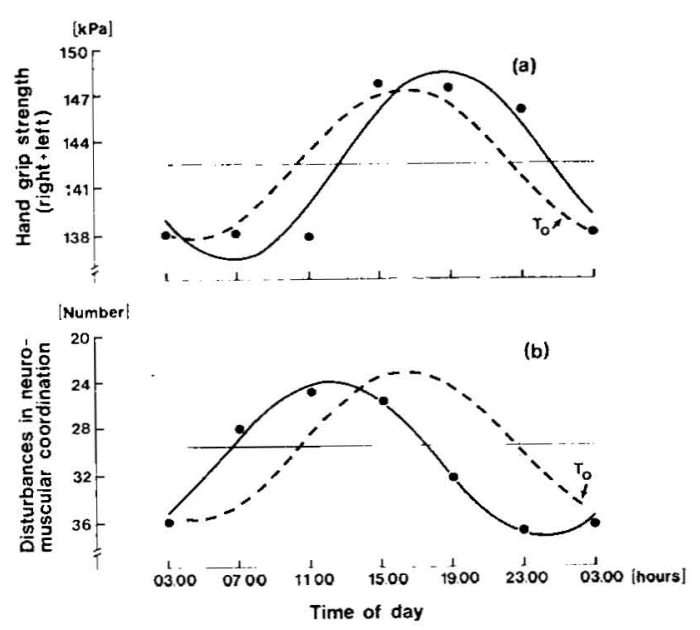

Fig 2. Fourier curves of the average hourly responses of the hand grip strength, left and right combined (a) and neuromuscular coordination, left and right combined (b). The broken lines represent the Fourier curve of oral temperature.

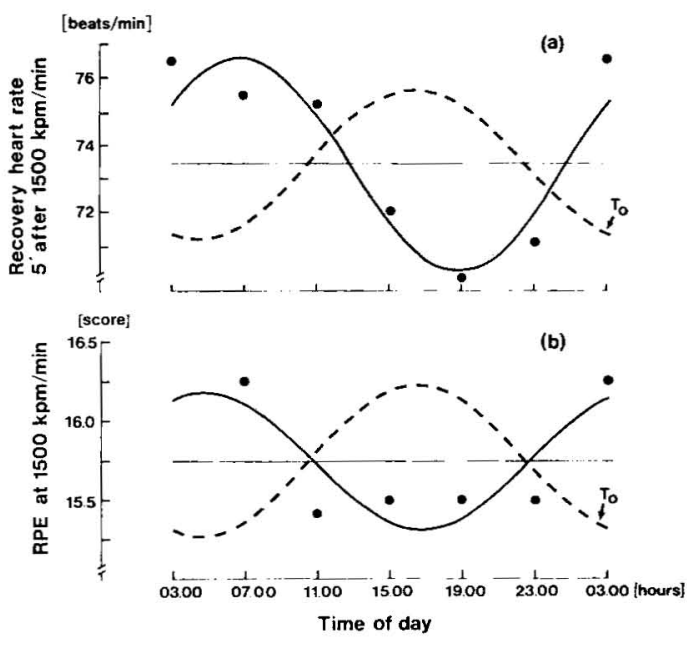

Fig 3. Fourier curves of the average hourly responses of heart rate recovery after 1,500 $\mathrm{kpm} / \mathrm{min}(245 \mathrm{~W})$ (a) and of the ratings of perceived exertion at $1,500 \mathrm{kpm} / \mathrm{min}(245 \mathrm{~W})$ (b). The broken lines represent the Fourier curve of oral temperature. 
Its variation was also similar to that found in earlier studies $(8,10)$. This occurrence allowed us to compare the responses of other variables with that of $T_{0}$. The phase angle of systolic blood pressure and heart rate at rest and during work very much resembled that of $T_{0}$ (fig $\left.1 a-d\right)$. The hand grip strength and neuromuscular coordination were also roughly in phase with $T_{0}$ (fig $2 a-b$ ). The rhythms of perceived exertion and heart rate recovery seemed to be more or less inversely related to $T_{0}$ so that the physical work was perceived as the heaviest and the recovery heart rate was the slowest at the same time that the minimum value of $T_{n}$ was reached (fig $3 a-b)$. These phase similarities and differences with $\mathrm{T}_{0}$ are interesting and, according to Rutenfranz \& Colquhoun, conceivable.

The circadian circulatory responses of heart rate at rest and during work obtained in this study confirmed those of earlier studies $(3,7,8)$. In interpreting the heart rate responses, it should be pointed out that the heart rate at night is not low because of less strain but because circadian rhythm exists. Therefore a response curve due to external stress such as muscular work on a bicycle ergometer is different throughout a 24-h period. These differences in responses should not however be related to the absolute level of heart rate (because it is markedly lower at night than during the day), but they are much better demonstrated, for example, by the response of the heart rate at recovery (fig 3a). The recovery heart rate after the work load of $1,500 \mathrm{kpm} / \mathrm{min}(245 \mathrm{~W})$ was the slowest at 0300 and 0700 . Interestingly, at the same times, the work was perceived to be the heaviest (fig $3 \mathrm{~b}$ ). This relationship between rating of perceived exertion and recovery heart rate thus provides an explanation for the complaints made by shift workers. Physical work at night is not only subjectively (rating of perceived exertion) but also objectively (heart rate recovery) heavier than during the day. In order to study the stress and strain in a real shift work situation, one should take into consideration the rating of perceived exertion and recovery heart rate.

The circadian rhythm of heart rate is maintained from a resting level to a high work level, although the difference be- tween the maximum and minimum responses become smaller as work level increases, eg, from rest with $15.6 \%$ to heavy work at $1,500 \mathrm{kpm} / \mathrm{min}(245 \mathrm{~W})$ with $2.6 \%$. Because of this circadian rhythm of heart rate during work the calculations of $\mathrm{VO}_{2}$ max based on a submaximal exercise test at night are misleading. Although a linear relationship between heart rate and work load can be used for calculations, the $\mathrm{VO}_{2} \max$ will be overestimated at night (7).

The direct measurements of $\mathrm{VO}_{2}$ at three submaximal work loads showed no circadian variation in $\mathrm{VO}_{2}$ at the level of 1.75 to $3.45 \mathrm{l} / \mathrm{min}$. This result agrees with the results reported for the level of 2.4 to 4.4 $1 / \mathrm{min}$ or at work loads of $600-700 \mathrm{kpm} /$ $\min (98-114 \mathrm{~W})(6,7)$ and suggests that no circadian rhythm exists for oxygen consumption at standard submaximal physical work loads.

The minimum (occurring at 0500) and maximum (at 1700) values for the systolic blood pressure of our subjects (fig $1 \mathrm{~b}$ ) were situated rather similarly to those of the normotensive subjects investigated by Millar-Graig et al (12); their subjects were measured continuously with the intraarterial technique during normal daily activities. They found that the lowest blood pressure occurred at 0300 and began to rise during the early morning before waking. It attained its maximum already in the morning and remained fairly constant between 0900 and 1900 and then fell progressively to its minimum at night. However, no overall harmonic oscillation of diastolic blood pressure was found. One possible explanation for this lack of oscillation could be confounding factors, eg, seasonal differences (October vs February) or the temperature of the room air.

The grip strength of our subjects showed a circadian variation very similar to that of $\mathrm{T}_{0}$. For example the highest values were found at 1500 and 1900 when $T_{0}$ was at its maximum (fig 2a). The times when the minimum and maximum occurred were similar to those reported by Reinberg et al (14).

The estimated number of disturbances in the task of neuromuscular coordination (balance board test) was low from 1200 to 1300 , while oral temperature reached its maximum between 1600 and 1700 (fig $2 b$ ). The inverse rhythm is difficult to interpret 
because of the complex mechanism necessary for maintaining balance on the seesawing board. The test demands quick reactions for correcting body position. In more sensomotoric tasks reaction time has been found to be shortest at noon and especially long between 0000 and 0400 (11).

Whether this is the case also for the lower extremities and for a complex balance task is unknown and needs additional investigation. Knowledge concerning this possibility would be valuable according to the suggestion that a greater number of accidents occurs in industrial work when biological efficiency is low (13). The difference between the maximums and minimums in the balance test was also clearly the largest of all the variables in this study. The practical importance of this observation needs additional clarification from the point of view of occupational safety.

In summary, the most meaningful physiological finding of the present investigation was the circadian variation of perceived exertion during physical work, of heart rate recovery after work, and of performance of a neuromuscular coordination task. Physical work was perceived to be the heaviest and the recovery from stress the slowest at night. The difference between the maximum and minimum response in a task needing active neuromuscular coordination was $44 \%$, and the maximum number of disturbances occurred at night. Generally, our results concerning the variables of muscle strength, neuromuscular coordination, perceived exertion, and recovery heart rate support the idea of a decrease in physical work capacity at night.

\section{Acknowledgment}

Our sincerest thanks go to Ms A-L Lähteenmäki for her assistance in the data collection and to $\mathrm{Mr} \mathrm{K}$ Nieminen for constructing the test equipment used for measuring hand grip strength and neuromuscular coordination. The cooperation of the four physical education students and the support of the Vierumäki Sports Institute made the study feasible. We are very grateful for their assistance.

This study was financially supported by the Finnish Ministry of Education.

\section{References}

1. Bliss CI. Periodic regression in biology and climatology. Connecticut Agricultural Experimental Station, New Haven CT 1958. (Bulletin 615).

2. Borg G. Perceived exertion as an indicator of somatic stress. Scand j rehabil med $2-3$ (1970) 92-98.

3. Cohen CJ, Muehl GE. Human circadian rhythms in resting and exercise pulse rates. Ergonomics 20 (1977) 475-479.

4. Colquhoun WP, ed. Biological rhythms and human performance. Academic Press, London and New York 1971.

5. Halberg F, Tong YL, Johnson EA. Circadian system phase - An aspect of temporal morphology; procedures and illustrative examples. In: Mayersbach $\mathrm{H}$, ed. The cellular aspects of biorhythms. Berlin 1967, pp 20-48.

6. Hildebrandt G, Engel P. The relation between diurnal variations in psychic and physical performance. In: Colquhoun WP, ed. Aspects of human efficiency. The English University Press, London 1972, pp $231-240$.

7. Ilmarinen $J$, Rutenfranz $J$, Kylian $H$, Klimt F. Untersuchungen zur Tagesperiodik verschiedener Kreislauf- und Atemgrössen bei submaximalen und maximalen Leistungen am Fahrradergometer. Eur j appl physiol occup physiol 34 (1975) 255267.

8. Klein KE, Wegmann HM, Brüner H. Circadian rhythm in indices of human performance, physical fitness and stress resistance. Aerosp med 39 (1968) 512-518.

9. Kleitman N. Sleep and wakefulness. University of Chicago Press, Chicago, IL 1963.

10. Knauth $P$, Rutenfranz J, Herrmann G, Poeppl SJ. Re-entrainment of body temperature in experimental shift-work studies. Ergonomics 21 (1978) 775-783.

11. Mann H, Rutenfranz J, Aschoff J. Untersuchungen zur Tagesperiodik der Reaktionszeit bei Nachtarbeit: I. Die Phasenlage des positiven Scheitelwertes und Einflüsse des Schlafes auf die Schwingungsbreite. Int Arch Arbeitsmed 29 (1972) 159174.

12. Millar-Craig MW, Bishop CN, Raftery EB. Circadian variation of blood-pressure. Lancet 1 (1978) 8068, 795-797.

13. Nogueira DP. Accidents during work and time of day. Ind med 40 (1971) 28-30.

14. Reinberg A, Chaumont A-J, Laporte A. Circadian temporal structure of 20 shift workers (8-hour shift - weekly rotation): An autometric study. In: Colquhoun WP, Folkard S, Knauth P, Rutenfranz J, ed. Experimental studies of shift work. Westdeutscher Verlag, Opladen 1975.

15. Rutenfranz J, Colquhoun WP. Circadian rhythms in human performance. Scand $j$ work environ health 5 (1979) $167-177$.

16. Rutenfranz, J, Colquhoun WP, Knauth P, 
Ghata JN. Biomedical and psychosocial aspects of shift work. Scand $j$ work environ health 3 (1977) 165-182.

17. Tsaneva N, Dincheva E, Stojanova N. Changes in working capacity at night: Estimation of the maximum working capacity. In: National Institute of Occupational Health. Proceedings of the Second International Symposium on Night and Shift Work, Slanchey Bryag 1971. Stockholm 1972, pp 79-86. (Studia laboris et salutis report nr. 11).

18. Voigt E-D, Engel $P$, Klein $H$. Über den Tagesgang der körperlichen Leistungsfähigheit. Int $\mathrm{Z}$ Angew Physiol Einschl. Arbeitsphysiol 25 (1968) 1-12.

19. Wahlberg I, Åstrand I. Physical working capacity during the day and night. Work environ health 10 (1973) 65-68.

20. Wojtzak-Jaroszowa J, Banaszkiewicz A. Physical working capacity during the day and night. Ergonomics 17 (1974) 193-198.

Received for publication: 5 October 1979 